\title{
Acceptance of marijuana therapy prompts call for more research
}

San Francisco. In an unprecedented move, voters in California and Arizona last week passed laws approving the medical use of marijuana. Clinical research on the drug's usefulness for treating pain, nausea and loss of appetite in cancer, AIDS and other diseases has often been held up in the past for what many claim are political reasons.

Opponents of change in the laws had pointed out the lack of scientific evidence for therapeutic uses of the drug. But supporters seem to have won over voters with anecdotes of medical benefits, and the argument that anti-drug politics had repeatedly undermined efforts by scientists to quantify the drug's usefulness.

Indeed, the vote has stimulated a call for the US government to overcome its objections to research on the medical use of marijuana and to fund studies of its own.

The Arizona law is the broader of the two, allowing doctors to prescribe marijuana and other drugs designated as Schedule $1-$ which includes heroin and LSD - if they can offer scientific evidence that the drug is medically useful. The California rule allows a patient or 'care-giver' to grow and possess marijuana if it has been recommended, either orally or in a written prescription, by a doctor to treat a particular illness.

The California Medical Association (CMA) called the votes a mandate for research into both the potential therapeutic effects of the drug and its potential dangers. The association urged the National Institutes of Health (NIH) to conduct controlled studies. "It's not a law enforcement question, it's a scientific question," says Steve Thompson, vice-president of government affairs for CMA in Sacramento.

But the only federal response so far has been a promise by the Drug Enforcement Administration that it will continue to treat the cultivation and possession of marijuana as a felony. The CMA has warned doctors that, given strong federal laws, the state vote is primarily symbolic, and that doctors may face prosecution if they prescribe the drug.

The association has long acknowledged that marijuana could be of significant benefit to patients. But Thompson says that antidrug laws have made it impossible to carry out proper research. Meanwhile, he says, use among patients has become widespread.

The Federation of American Scientists has also called for research. But Mark Kleiman, a member of the federation's drug policy group, says he is not optimistic that the state laws will lead to an outburst of scientific activity.
"It's like being a flat-earther - it's not healthy for your career," says Kleiman, a policy analyst at the University of California in Los Angeles. Researchers have to seek assistance from the National Institute on Drug Abuse to obtain samples of the drug, and to overcome objections from drug enforcement agencies against marijuana as a drug of abuse.

One difficulty facing scientists carrying out experiments on marijuana is that they cannot be double-blinded, and dosage is difficult to measure and control. Donald Abrams, the most recent researcher to attempt a study, says he has encountered these obstacles and others in a four-year effort to win approval to analyse the effect of marijuana inhalation on AIDS wasting.

Abrams, who is assistant director of the AIDS programme at San Francisco General Hospital and professor of clinical medicine at the University of California, San Francisco, had won support for his trial from the Food and Drug Administration and from various advisory bodies in California.

But the NIH, whose support he needs to obtain the drug, last summer returned his proposal unrated. The NIH panel criticized the study's design, and complained that toxic effects of the drug - including the potential development of atherosclerosis in AIDS patients if they absorbed too many calories after smoking pot - might be ignored.

Steve Schnittman, assistant director of clinical research in the Division of AIDS at the National Institute of Allergy and Infectious Disease, declines to comment on Abrams's study, but says that his institute is concerned about the potential danger in such studies from toxic contaminants such as fungi. "We welcome good science, we just haven't gotten it yet," Schnittman says.

Abrams says that the new laws make research on the medical use of marijuana essential. Because research on the beneficial effects of marijuana appears to be so unpalatable to government agencies, he is planning to resubmit his study proposal to $\mathrm{NIH}$ as an analysis of toxicity.

Abrams says that in the past he had believed that he would eventually be able to carry out his experiments if the science he wanted to pursue could survive the pressures of politics. "Now, the politics may promote the science," he says. "It's a topsy-turvy turnaround." Sally Lehrman

\section{Car-maker turns to cannabis - for fibre}

London. As California and Arizona last week legalized the medical use of cannabis (above), scientists at the Daimler-Benz car company have declared their own interest in the hemp plant Cannabis sativa. The researchers have found that fibre from the plant (see right) can be used instead of glass fibre to reinforce plastic components in vehicles.

Manufacturers are beginning to replace fibre glass with natural alternatives, such as flax, because products containing fibre glass pose environmental problems during disposal. Recent German government legislation allowing cultivation of the fibrous hemp for industrial purposes has paved the way for research into using hemp fibres in place of fibre glass. The fibrous hemp holds only small quantities of the resin that contains what the company calls the "ignoble" drug.

\section{IMAGE \\ UNAVAILABLE FOR COPYRIGHT REASONS}

